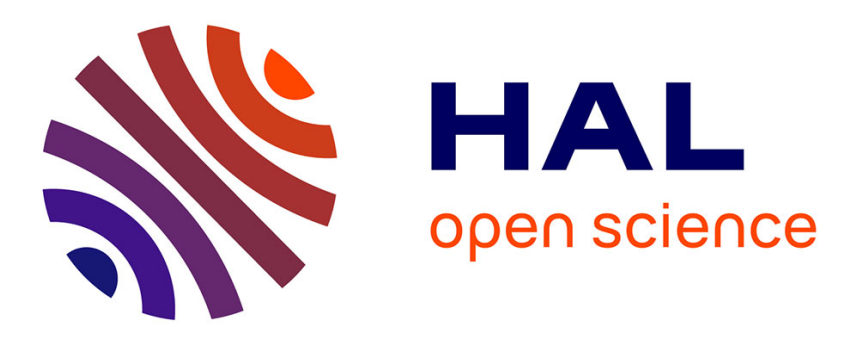

\title{
Design and simulation of turbo-alternators using coupled permeance network model
}

Dmitry Petrichenko, Michel Hecquet, Pascal Brochet, Vyacheslav Kuznetsov, Daniel Laloy

\section{- To cite this version:}

Dmitry Petrichenko, Michel Hecquet, Pascal Brochet, Vyacheslav Kuznetsov, Daniel Laloy. Design and simulation of turbo-alternators using coupled permeance network model. IEEE Transactions on Magnetics, 2006. hal-01715679

\section{HAL Id: hal-01715679 \\ https://hal.science/hal-01715679}

Submitted on 22 Feb 2018

HAL is a multi-disciplinary open access archive for the deposit and dissemination of scientific research documents, whether they are published or not. The documents may come from teaching and research institutions in France or abroad, or from public or private research centers.
L'archive ouverte pluridisciplinaire HAL, est destinée au dépôt et à la diffusion de documents scientifiques de niveau recherche, publiés ou non, émanant des établissements d'enseignement et de recherche français ou étrangers, des laboratoires publics ou privés. 


\title{
Design and simulation of turbo-alternators using coupled permeance network model
}

\author{
Dmitry Petrichenko, Michel Hecquet, Pascal Brochet, Vyacheslav Kuznetsov, Daniel Laloy
}

\begin{abstract}
The modelling of a turbo-alternator using permeance network is described. This approach allows implementing electrical and magnetic coupling as well as mechanical coupling. Such processes as saturation, movement, 3D effects are be taken into account. The aim of this study is to set up a design model of 10 to 100 MW turboalternators. The method of taking into account of 3D effects is described. The first results of simulation were obtained. The experimental measurements validate the model.

Key words - CAD application, reluctance network, magnetic circuit, magnetic field, air-gap permeance, automatic generation of the permeance network.
\end{abstract}

\section{INTRODUCTION}

The recent high growth of the power of the computer systems, development of the software to solve complicated problems made it possible to use precise methods of calculations in electric machinery to obtain the magnetic fields analysis. The most spread nowadays finite element method still demands too much computing power to obtain the results in a short time. Thus in the applications of optimization, where the calculation time is very important, one should use methods maybe a little bit less precise than FEM but more quick and effective.

Being based on a permeance network methods [1], [2] Tooth Contour Method (TCM) [3] gives one fast calculation of magnetic circuit and, therefore, high performance calculation of steady-state and dynamic characteristics and transient analysis. This feature allows TCM to be used in CAD systems. The peculiarity of the method is in special air-gap permeances calculations and the electrical-magnetic coupling treatment. A software implementation of the method realizes an automatic parameterized permeance generation. A same circuit description tool can generate both electric and magnetic network, providing then the calculations of the machine coupled with electrical parts.

In the first part, the basis of the Tooth Contour Methods is given and the mathematical model of turbo alternator is presented. Then, the calculation strategy is given and also the structure of the software 'TurboTCM'.

Manuscript received 20 June 2005. This work was supported by C.N.R.T. Réseaux et Machines Electriques du Futur (Projet 'Archimed') and JEUMONT SA (Framatome).

D. Petrichenko is with L2EP, Ecole Centrale de Lille, Cite scientifique, BP48, 59651 Villeneuve d'Ascq Cedex, France (phone: +33.320.67.60.20; e-mail: Dimitry.Petrichenko@ec-lille.fr)

M. Hecquet is with L2EP, Ecole Centrale de Lille, Cite scientifique, BP48, 59651 Villeneuve d'Ascq Cedex, France (e-mail: Michel.Hecquet@ec-lille.fr)

P. Brochet is with L2EP, Ecole Centrale de Lille, Cite scientifique, BP48, 59651 Villeneuve d'Ascq Cedex, France (e-mail: Pascal.Brochet@ec-lille.fr)

V. Kuznetsov is with Moscow Power Engineering Institute (MPEI), Dep. of Electromechanics; Krasnokazarmennaja, 13, Moscow, 111250, Russia (e-mail: KuznetsovVA@mpei.ru)

D. Laloy is with JEUMONT SA (Framatome), 27 Rue de l'Industrie, BP189, 59573, Jeumont Cedex, France

\section{PERMEANCE NETWORK AND TOOTH CONTOUR METHOD}

Different methods using magnetic equivalent circuit to represent the field inside the electrical machine are detailed in [3], [4]. The main advantage of this approach is a good compromise between the accuracy of field calculations and the computing time. In this method, the $3 \mathrm{D}$ effects of a field in the electrical machine are easily taken into account with accuracy enough for practical purposes [4].

The Tooth Contours Method represents one approach of permeance networks. It is based on theoretically validated representation of the total magnetic field in the air-gap as the sum of local magnetic fields of the particular elements of the so-called tooth contours [5]. Usually the tooth contour is considered to be an element formed by the conductors located in adjacent slots, but it may be also represented as any part of the core surface e.g., the pole-shoe may be divided into several "tooth" contours (Fig. 1).

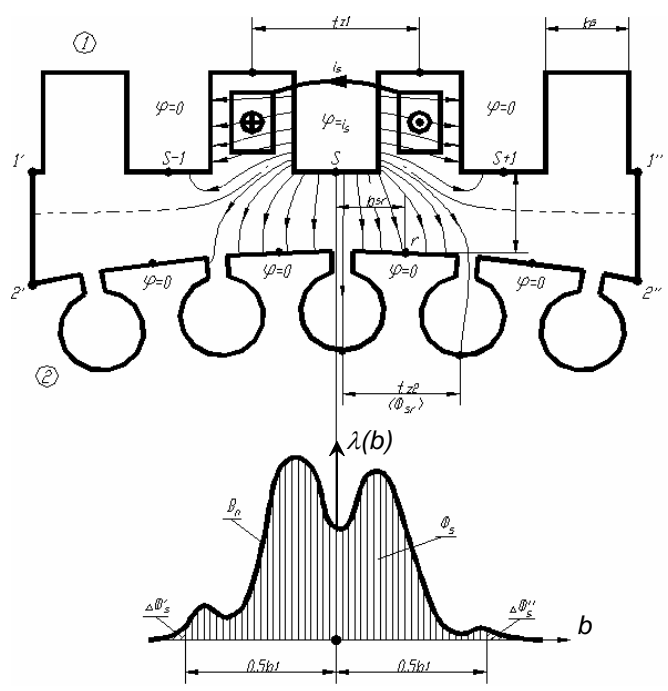

FIG. 1 TOOTH CONTOUR REPRESENTATION

The local magnetic fields of tooth contours are to be calculated under the artificial boundary conditions, called the Special Boundary Conditions (SBC), supposing that the permeability both of stator and rotor iron is infinitely large. This special field is localized in a small region, which usually does not exceed three or four tooth pitches and so it could be easily and quickly calculated. As a result, a mutual permeance between excited contour $s$ of a stator and one of a non-excited rotor contours $r$ are obtained as a function of their relative position $\lambda_{\mathrm{sr}}\left(\mathrm{b}_{\mathrm{sr}}\right)$, as shown on Fig.1. 


\section{Air-gap permeances}

To calculate the air-gap permeances one has to calculate the magnetic field in the air-gap region. The field calculations can be performed by many different methods. Here an analytical method of calculations is given [5].

The curvilinear air-gap is transformed into the plane using conformal transform function. The following assumptions are applied:

- the slots' form is not taken into account, they are considered to be rectangular with the width equal to the width of the slits;

- the field is considered to be 2D;

The method shown above has been validated for a small region using OPERA [http://www.vectorfields.com]. The results can be found in [6].

\section{Magnetic system permeances}

The permeance network of the magnetic systems of stator and rotor is generated automatically based on parameters of the geometry. The general structure of the permeance network of the stator is presented on the Fig. 2.

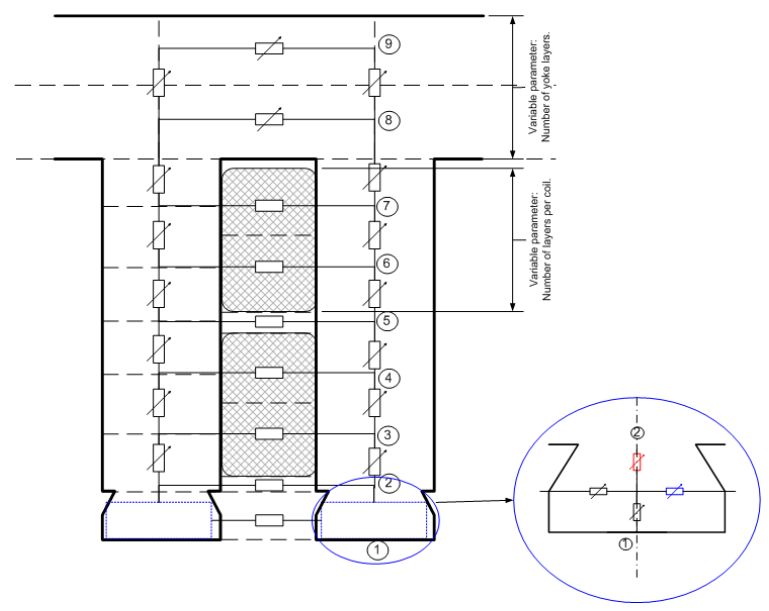

FIG. 2 STATOR EQUIVALENT CIRCUIT

The number of layers in the stator yoke and number of layers in the teeth zone is variable. That variable influences both on the calculation accuracy and time.

The rotor of a turboalternator can have rather sophisticated structure and geometry, as different dimensions of the slots and teeth, etc. The software under development generates the equivalent circuit completely automatically taking all these difficulties into account.

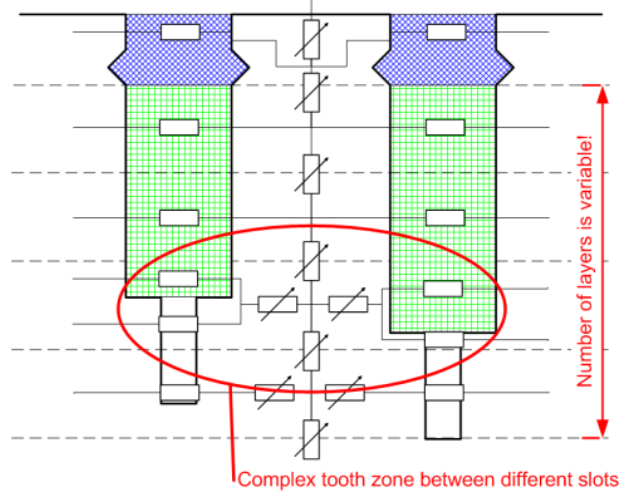

FIG. 3 ROTOR EQUIVALENT CIRCUIT

Fig. 3 shows the equivalent circuit of one tooth of the rotor where the heights of the adjacent slots are different.
The software analyzes the geometry of the inter-slot space and generates the circuit for the particular zone automatically. The user can define the number of layers (which affects the accuracy of calculations).

The sources of MMF are situated in the horizontal branches and are not presented on Fig. 2 and Fig. 3.

\section{Taking into account $3 D$ effects}

In modern turboalternator of high power stator and/or rotor have radial ventilation ducts which should affect a lot on the magnetic permeance network of the model. Besides, stator usually is made of laminated steel with its filling factor. All those facts show that pure 2D representation of the fields in an electrical machine is not correct; pure crosssection without taking into account the axial heterogeneity of the machine is impossible.

To take into account these effects in the permeance network the permeances must be modified in order to reflect axial effects in the network.

Taking into account the reduction of the axial length of steel caused by the existence of radial ventilation ducts and steel filling factor is rather simple. The magnetic field calculation in two-dimensional representation one should perform not for a real magnetization curve $B(H)$ but for the one with the reduced component $B$ in the following proportion: the axial steel length by full axial length of the cores including the length of the ventilation ducts.

For the flux densities exceeding 1.8-2.0 $\mathrm{T}$ another correction should be added to the curve obtained, caused by the flux bulging into the inter-sheet non-magnetic space in the steel packets. The gap between the sheets being determined by the thickness of the insulation layer usually doesn't exceed $10-15 \%$ of the thickness of the sheet itself. Thus, the flux bulging plays a noticeable role only in the zone of high saturation. It can be calculated using the same method as one to obtain a new magnetizing characteristic of teeth with flux bulging into slots supposing that the magnetic flux lines are parallel inside a tooth and a slot. That formula is well-known as can be found in the books of electrical machine design.

Other areas where the correction of the permeances should be applied are the ones with air. These zones are the slots of stator and rotor and the air-gap, the last one having the most influence of ducts both on stator and on rotor.

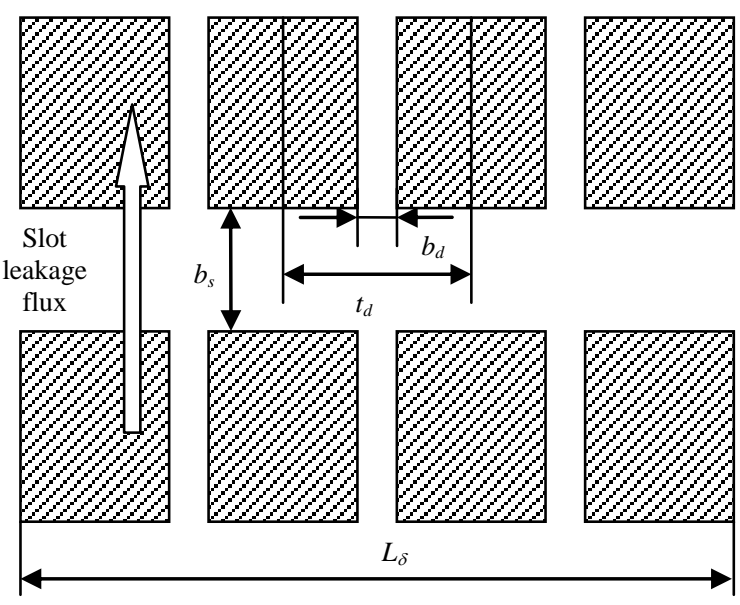

FIG. 4 SLOTS AND DUCTS REPRESENTATION

The influence of ventilation ducts in slot zone is very important for the slot top leakages. The cross-section of a 
slot on some radius is shown on Fig. 4 , where: $b_{s}-$ slot width, $b_{d}$ - duct width, $t_{d}$ - duct pitch, $L_{\delta}$ - core length in axial direction. To obtain correct values of permeances in these zones a modification of zones' permeability should be applied, which would reflect the axial heterogeneity of the cores. Since the air zones in machine contain only linear elements, the modification of the permeability can be achieved by correcting the effective length of the zones.

In simple case, a well-known Carter factor can be used. This factor reflects the influence of core's saliency on the air-gap. A modified Carter factor calculation is shown below:

$$
K_{\text {slot }}=t_{d} \cdot\left(t_{d}-\frac{b_{s}^{\prime} \cdot\left(\frac{b_{d}}{b_{s}^{\prime}}\right)^{2}}{5+\frac{b_{d}}{b_{s}^{\prime}}}\right)^{-1}
$$

where: $b_{s}{ }^{\prime}=0.5 \cdot b_{s}-$ half of the slot width.

This factor is applied to the length of the slot zone for the whole slot if the slot is rectangular. It may vary from layer to layer if the slot is trapezoidal or has any other form. The obtained length is:

$$
L_{\text {effs }}=\left(L_{\delta}+2 \cdot b_{s}\right) \cdot K_{\text {slot }}^{-1}
$$

In formula (2) an additional length equal to $2 b_{s}$ is added to the core length $L_{\delta}$ in order to take into account the edge effects. By means of (1) and (2) the modified zones' lengths are obtained for stator and rotor cores.

The same method is used to determine the influence of the ducts on the permeances of air-gap except that stator and rotor may have both different lengths and different number of ducts with different sizes as shown on Fig. 5.

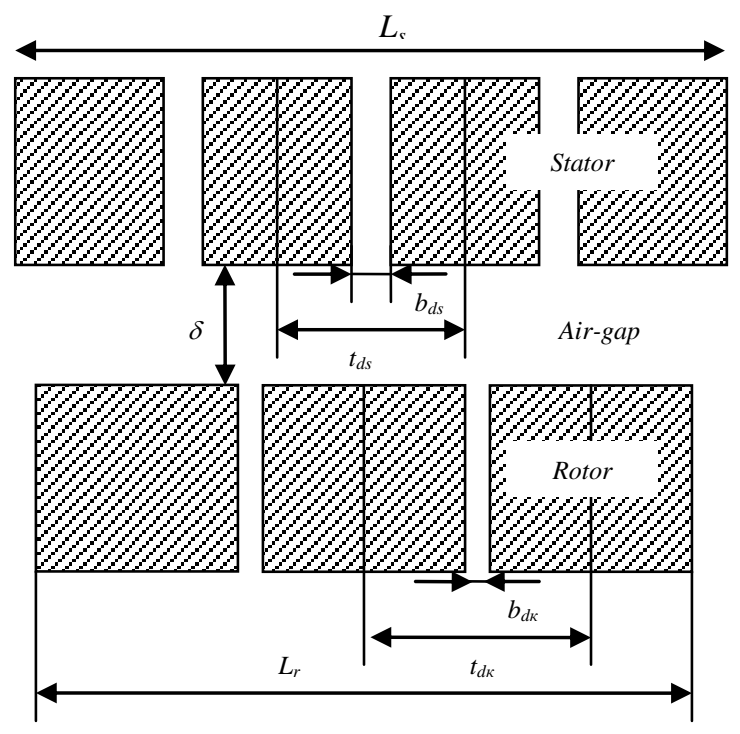

FIG. 5 DUCTS AND AIR-GAP ZONE

In this case the Carter factor is considered as following:

$$
K_{\delta s}=t_{d s} \cdot\left(t_{d s}-\frac{\delta \cdot\left(\frac{b_{d s}}{\delta}\right)^{2}}{5+\frac{b_{d s}}{\delta}}\right)^{-1}
$$

$$
K_{\delta r}=t_{d r} \cdot\left(t_{d r}-\frac{\delta \cdot\left(\frac{b_{d r}}{\delta}\right)^{2}}{5+\frac{b_{d r}}{\delta}}\right)^{-1}
$$

The length of the air-gap will be influenced both by (3) and (4):

$$
L_{\text {eff } \delta}=\left(\max \left(L_{s}, L_{r}\right)+2 \cdot \delta\right) \cdot K_{\delta s}^{-1} \cdot K_{\delta r}^{-1}
$$

Actually, formula (5) contains both the influence of ventilation ducts and the edge effects.

\section{CALCULATIONS AND SOFTWARE REALIZATION}

The software has been designed to perform the calculations both in dynamic and steady-state modes. The dynamic algorithm is rather simple and consists of calculating the system of equations using regular timestepping method. The steady-state calculations algorithm with fixed rotor has been implemented for steady-state mode characteristics calculation.

The software (TurboTCM) implementation of the method described earlier consists of several layers. As an input data one has a full specification of the turboalternator: stator and rotor sizes, number of stator and rotor slots, their dimensions, insulation, full description of the stator and excitation windings, characteristics of the materials, specification of the electrical part, etc. Fig. 6 presents one of the input windows. Based on that information, the software automatically generates the parameterized magnetic equivalent circuit, electric circuit and coupling equations.

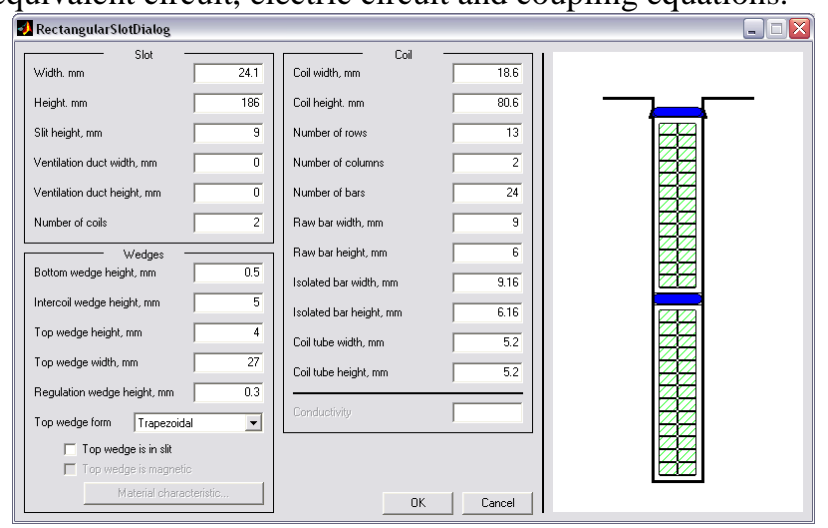

FIG. 6 TURBOTCM: SLOT PARAMETERS INPUT DIALOG

'TurboTCM' has been implemented in Matlab and used Component Object Model (COM) technology. To take into account the saturation a well-known Newton-Raphson algorithm has been used.

\section{SIMULATION RESULTS AND COMPARISONS WITH EXPERIMENTS}

In first time, 'TurboTCM' has been experimented on a classical machine. Obtained results and their comparison with the finite element simulation have been presented in [6], [7]. The gain of time calculation in TurboTCM comparing with the field methods was 600 times.

The experimental results were obtained for a 2-poles turboalternator, which cross-section is presented on Fig. 7. 


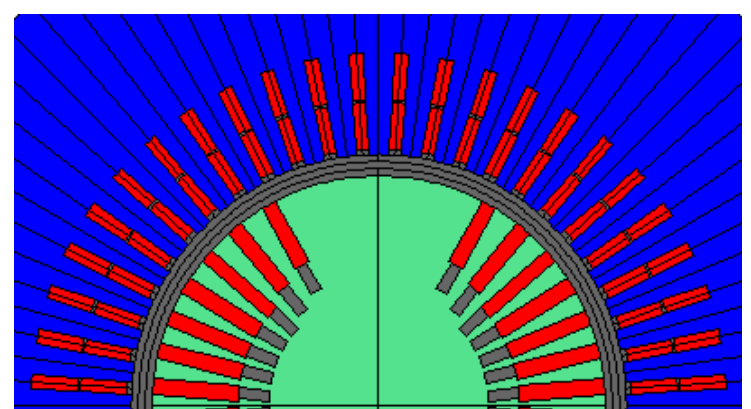

FIG. 7 TURBOALTERNATOR CROSS-SECTION

The turboalternator has 48 slots on stator and 28 slots on rotor. The stator has a double braid winding with the step $y=5 / 6$. The peculiarity of this machine is that the rotor slots are not evenly distributed and have different heights.

\section{Steady-state analysis}

The steady-state analyses have been performed using the method with fixed rotor, which was described in [6]. The results are shown on the Fig. 5. The experiment and simulation results are quite close. The maximal error is $6.58 \%$. For the excitation current equal to nominal, error is $0.286 \%$.

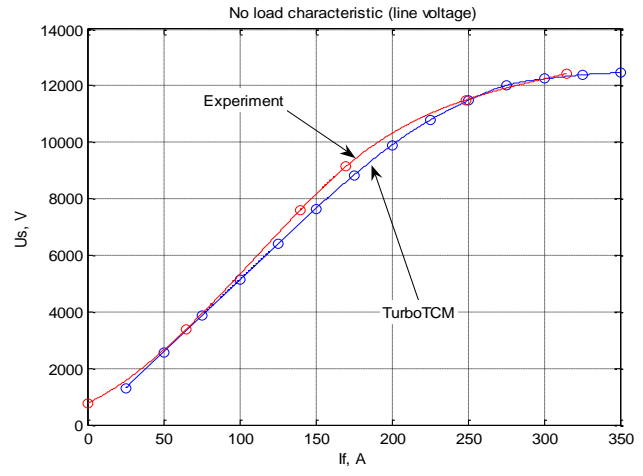

FIG. 8 NO-LOAD CHARACTERISTIC COMPARISON

Fig. 6 shows the comparison of no-load curves depending on different number of layers in stator and in rotor.

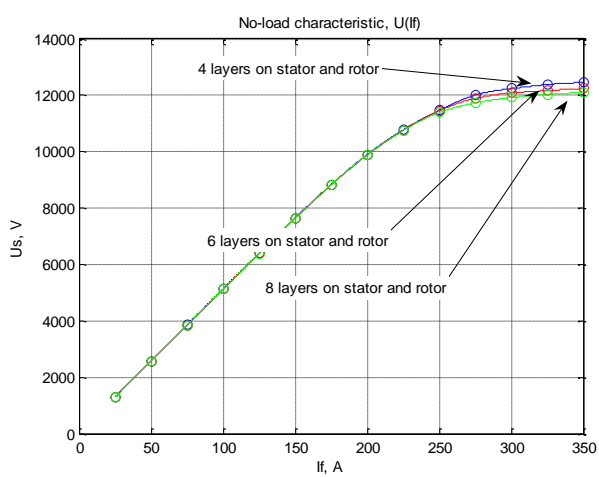

FIG. 9 NO-LOAD CHARACTERISTICS DEPENDING ON LAYERS

The greater the number of layers, the more precise calculation of saturated part is. However, the difference between 6 and 8 layers is negligible and in most cases 5-6 layers is sufficient enough for practical use.

\section{Dynamic analyses}

The dynamic analysis has been performed for no-load case on a full period of $360^{\circ}$ with the step of $2^{\circ}$ for a speed of $3600 \mathrm{tr} / \mathrm{min}(60 \mathrm{~Hz})$ and nominal excitation current of $250 \mathrm{~A}$. The results are presented on Fig. 10. Calculation time is $77.9 \mathrm{sec}$.

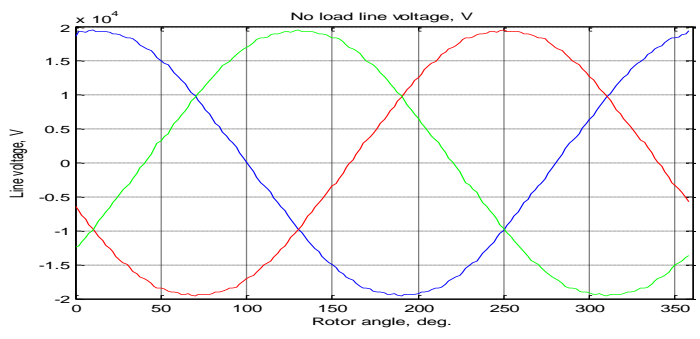

Fig. 10 LinE VOLTAGES OBTAINED By TURBOTCM

The RMS value of line voltage is $13825 \mathrm{~V}$ while in experiments $13803 \mathrm{~V}$ is obtained. The error is $0.16 \%$.

Table 1 presents the harmonic levels in percents of the first harmonic for the simulation results.

TABLE 1

COMPARISON OF HARMONIC LEVELS OF STATOR VOLTAGE

\begin{tabular}{|c|c|}
\hline \hline \multirow{2}{*}{ Harmonic level } & Line voltages, \% \\
\cline { 2 - 2 } & TurboTCM \\
\hline 2 & 0.0004 \\
\hline 3 & 0.0006 \\
\hline 4 & 0.0008 \\
\hline 5 & 0.8670 \\
\hline 6 & 0.0012 \\
\hline 7 & 0.0204 \\
\hline 47 & 0.1893 \\
\hline 49 & 0.2567 \\
\hline \hline
\end{tabular}

\section{CONCLUSION}

In this work the model of a synchronous machine based on a tooth contour method was presented along with the software TurboTCM. The method of taking into account the 3D effects was described. The first results of simulation were compared and validated with those of experiments for no-load case. The comparison show good correspondence between the calculation results and the experimental data.

While realizing a good compromise between accuracy and computing time, this model opens the way to optimal design of turbo-alternators.

\section{REFERENCES}

[1] Ostovic V., "Dynamics of saturated machines", Springer-Verlag, 1989.

[2] Worotynski J., Turowski M., and Mendrela E.A., "The accuracy of calculation of magnetics fields, inductance and forces in electromagnetic devices using the reluctance network method", Proc.ISEF'93, Warsaw, pp159-162, 1993.

[3] Kuznetsov V., Brochet P., "A general numerical modelling of electromagnetic process in electromechanical systems", The International Journal for Computation and Mathematics in Electrical and Electronic Engineering (COMPEL), Vol. 22, No. 4, pp 1142-1154, 2003.

[4] Hecquet M., Brochet P., "Time variation forces in a synchronous machine using electric coupled network model", IEEE Trans. On Magnetics, Vol. 34, No 5, pp 3656-3659, September 1998.

[5] Ivanov-Smolenskii A. and authors, "Universal Method of Electromagnetic Processes Calculations in Electrical Machines", Energoatomizdat, 1986, Moscow, Russia.

[6] D. Petrichenko, Michel Hecquet, Pascal Brochet, Vyacheslav Kuznetsov, Daniel Laloy, 'Numerical modelling of a turboalternator using Tooth Contours Method: CAD application', ICEM 2004, CD Rom, Cracovie, 5-7 Oct. 2004.

[7] D. Petrichenko, M. Hecquet, P. Brochet, V. Kuznetsov, D. Laloy, "Development of the turboalternator simulation software", ELECTRIMACS 2005, CD-ROM, Hammamet, Tunisia, 17-20 April, 2005 . 